\title{
Long-term effect of cognitive-behavioural therapy in patients with Hypochondriacal Disorder
}

Kari-Elise Frøystad Veddegjærde, Børge Sivertsen, Jens Christoffer Skogen, Otto Robert Frans Smith and Ingvard Wilhelmsen

\section{Background}

Cognitive-behavioural therapy (CBT) is an effective treatment for Hypochondriacal Disorder, but the long-term effect has not been examined extensively.

\section{Aims}

To investigate the long-term effect of CBT on Hypochondriacal Disorder using several mental health measures. Follow-up time was at least 10 years.

\section{Method}

A total of 50 patients with a long history of Hypochondriacal Disorder, diagnosed according to ICD-10, received 16 sessions of individual CBT and were followed up with an uncontrolled design. All participants were assessed before and after the intervention period, and 10 years later. Intention-to-treat mixedmodel repeated-measures analysis were conducted. The study has been registered at clinicaltrials.gov: NCT00959452.

\section{Results}

Patients displayed significant improvements across all outcomes, including level of health anxiety, somatisation, symptoms of anxiety and depression, quality of life, somatisation at treatment completion. Treatment gains were well maintained 10 years later.

\section{Conclusions}

This uncontrolled treatment study suggests that patients treated with CBT for Hypochondriacal Disorder have significantly reduced health anxiety 1 year after treatment completion and the results are maintained 10 years later. The results indicate that CBT has a lasting effect, but the lack of a control group and use of only one therapist, means that care should be taken when generalising the findings.

\section{Keywords}

Cognitive behavioural therapies; anxiety disorders; outpatient treatment.

\section{Copyright and usage}

(c) The Author(s) 2020. This is an Open Access article, distributed under the terms of the Creative Commons Attribution-

NonCommercial-NoDerivatives licence (http://creativecommons. org/licenses/by-nc-nd/4.0/), which permits non-commercial re-use, distribution, and reproduction in any medium, provided the original work is unaltered and is properly cited. The written permission of Cambridge University Press must be obtained for commercial re-use or in order to create a derivative work.

\section{Hypochondriacal Disorder}

Hypochondriacal Disorder, or excessive health anxiety, involves persistent preoccupation with excessive worrying about having or getting a serious illness. ${ }^{1}$ The patients focus on physical symptoms, keep track of all bodily changes and usually misinterpret these as signs of a serious illness. ${ }^{1,2}$ The worry and bodily preoccupation persists despite appropriate medical evaluation and reassurance. ${ }^{2,3}$ The prevalence of Hypochondriacal Disorder varies greatly across studies, but has been found to be as high as $5.7 \%$ for lifetime Hypochondriacal Disorder, and 3.4\% for current Hypochondriacal Disorder. ${ }^{2,45}$ The prevalence is substantially higher in primary care settings than in the general population. ${ }^{2}$ Of note, in the latest revision of the DSM (DSM-5), the diagnosis of Hypochondriacal Disorder or hypochondriasis has been replaced by illness anxiety disorder.

Untreated Hypochondriacal Disorder has a significant negative impact on the life of the people affected, with studies showing higher levels of comorbidity, distress, functional impairment and increased risk of sick leave for patients reporting Hypochondriacal Disorder. ${ }^{5}$ Patients with Hypochondriacal Disorder also have a higher level of healthcare utilisation, up to $78 \%$ higher than patients with well-defined medical conditions. ${ }^{6,7}$ These findings indicate that not only has Hypochondriacal Disorder a major impact on the lives of those affected, but it also represents a considerable cost for society. ${ }^{8}$ This was supported by the finding in a large Norwegian population study that Hypochondriacal Disorder was a potent risk factor for future permanent disability pension. ${ }^{9}$

\section{Treatment of Hypochondriacal Disorder}

Hypochondriacal Disorder was long thought of as an untreatable, lifelong condition. However, over past decades several studies have shown beneficial short-term effect of cognitive-behavioural therapy (CBT) for Hypochondriacal Disorder ${ }^{10,11}$ but there is still a paucity of studies examining if treatment gains are maintained over time. To the best of our knowledge, only one study has followed patients with Hypochondriacal Disorder beyond 1.5 years after treatment completion. ${ }^{11-13}$ In a 5 -year follow-up study of 444 UK patients with Hypochondriacal Disorder, Tyrer et al found CBT to be a highly effective treatment in reducing levels of health anxiety, as well as symptoms of anxiety and depression at follow-up. ${ }^{11}$

\section{Study aim}

Based on these considerations, the aim of the current study was to evaluate both the short- (18 months) and long-term (10 years) effect of CBT on Hypochondriacal Disorder across different mental health outcomes. The study has been registered at clinicaltrials.gov with the protocol identifier NCT00959452.

\section{Method}

\section{Study design and participants}

The study had an uncontrolled, repeated-measures design. Patients were selected from the Hypochondriac Clinic at Haraldsplass Deaconal Hospital, in Bergen, Norway, from 1996 to 2001. The 
clinic opened in 1995, only 1 day a week. The clinic receives patients from all of Norway after referral from general practitioners, medical specialists or psychologists. Patients from Bergen were offered 16 sessions of CBT whereas patients from other parts of Norway were offered fewer sessions. Before treatment the patients were diagnosed using the World Health Organization's Composite International Diagnostic Interview (CIDI), ${ }^{14}$ a structured interview for psychiatric disorders according to ICD-10. ${ }^{1}$ All patients fulfilled the diagnostic criteria for Hypochondriacal Disorder $(\mathrm{F} 45.2)^{1}$ as their primary diagnosis. Patients were excluded if they had a serious somatic illness, had psychosis or were diagnosed with alcohol and/or substance misuse.

Baseline data were collected at the start of therapy and all patients received 16 sessions of individual CBT, each session lasting 45-50 min, given over a period of 8-12 months. Patients were included in the long-term follow-up study at the scheduled control 1 year after the last session and because of the relatively long treatment and follow-up period only patients from the Bergen area were included in the study. The first 50 patients who fulfilled the diagnostic criteria for Hypochondriacal Disorder, had not developed any serious somatic disease during the treatment period and agreed to participate in the long-term follow-up were included. Two patients withdrew during the follow-up period and their data were excluded from the analysis. No patients died during the study period.

One therapist (I.W.) treated all the patients in this study. I.W. was educated in CBT ad modum Aaron Beck, and he is a certified supervisor of CBT in The Norwegian Association of Cognitive Therapy and a member of Academy of Cognitive Therapy. The therapist did not focus on the physical symptoms presented, but rather examined and questioned how the patients interpreted their symptoms. Research has found that reassurance has a negative effect on Hypochondriacal Disorder, ${ }^{15}$ which is supported by the fact that the patients in this study had the condition for more than a decade, in spite of numerous consultations with doctors, multiple tests and medical examinations.

The patients in this study differed in many ways, but the themes focused on in therapy were the same for all of them. The patients' metacognitions on rumination and worrying were always examined. It became clear that the patients tried to control factors that are in principle uncontrollable, ${ }^{16}$ such as death and the future. The patients were told that they cannot choose whether they have or will get a serious somatic disease or not, but they can choose what to believe, until further notice. Even though they had to make this decision with some doubt, they were asked not to make a doubtful decision. Thus, the patients were challenged to accept uncertainty as a given fact of life, and spend their life on living rather than on not dying. If the patient adopted new attitudes toward subjective symptoms, worrying, death and uncertainty, their homework assignment was to behave as if they meant it, in other words start doing things they had avoided before.

All patients completed a range of self-reported questionnaires at three assessment points: before (pre-CBT) and after (post-CBT) receiving the treatment, and at the 10 -year follow-up. The preand post-CBT forms were completed at the hospital, whereas the 10 -year follow-up assessment was by postal mail and telephone interview. In addition to data collected during the intervention study, we also used data on quality of life from a national representative sample of 3500 Norwegians. More details on this norm study has been published elsewhere. ${ }^{17}$

\section{Ethics and consent}

The study protocol was cleared by the Regional Committee for Medical Research Ethics of Western Norway and approved by the Norwegian Data Inspectorate. Informed consent in writing was obtained from all participants included in this study. All patients could withdraw from the study at any time, without giving any reasons for why they might want to withdraw from the study. This would not affect their further therapy.

\section{Instruments and measures}

Whiteley Index, 14-item and 6-item versions

The Whiteley Index, a 14-item Likert questionnaire, is a self-report measure to screen for Hypochondriacal Disorder. It was first used by Pilowsky in 1969, and has been widely used for the screening of Hypochondriacal Disorder. ${ }^{18}$ The Whiteley Index has been found to have good psychometric properties, although the factor structure has been questioned. ${ }^{19}$ The Whiteley Index consists of 14 items that originally were used dichotomously (true/false). A 5-point Likert scale version was later established, with the response options labelled as follows: 1 , 'not at all'; 2 , 'to some extent'; 3 , 'moderately'; 4 , 'to a considerable extent'; and 5 , 'to a great extent'. The dichotomous version of the Whiteley Index is still the version mostly used, although the Likert scale version is claimed to differentiate better than the dichotomous version. ${ }^{20}$ The version employed in the current study includes the Likert scaled response options. In a recent Norwegian study a shorter version of the Whiteley Index, including only six items, was found to have better psychometric properties than the original 14 -item version. ${ }^{19}$ In the current study, both the 6-item and the original 14-item Whiteley Index were used. Cronbach's alphas were 0.93 at all three assessment points.

\section{Next-of-kin questionnaire}

For the purposes of the present study, we adapted the Whiteley Index to be filled out by the participants' partner or a close relative. This next-of-kin-questionnaire is a Likert-scale questionnaire, with a response scale of $1-5$, where 1 equals 'not at all', and 5 is 'to a great extent', similarly to the Whiteley Index. The questionnaire estimates the patient's health complaints from a next-of-kin perspective. The Cronbach's alphas in the current study were 0.81 pre-CBT, 0.89 post-CBT and 0.93 for the 10 -year follow-up.

\section{The Short Form Health Survey}

The Short Form 36 Health Survey (SF-36) is one of the most used generic questionnaires for measuring quality of life and is often referred to as the 'gold standard' within research on health-related quality of life. The SF-36 includes 36 questions that are summed into eight multi-item subscales. The raw scores are transformed into a scale of 1-100, where low scores indicate lower quality of life, and high scores indicate higher quality of life, and the lower the score, the more disability. ${ }^{21}$ The Norwegian translation of the SF-36 has shown good reliability and validity. The norms used in this paper were weighted to match the gender and age distribution in the range of patients with Hypochondriacal Disorder. ${ }^{17}$

\section{Visual analogue scales}

Three visual analogue scales (VAS) were used to assess Hypochondriacal Disorder. Each of the three scales comprising a millimetre scale from 0 to 100 , where 0 represents optimal health/ no Hypochondriacal Disorder, and 100 represents bad/severely bad health/Hypochondriacal Disorder. The three VAS included:

(a) the tendency of Hypochondriacal Disorder over the past 2 weeks;

(b) the tendency to check their body over the past 2 weeks; and

(c) the tendency to think of certain symptoms and bodily changes over the past 2 weeks. $^{22}$

\section{The Beck Depression Inventory}

The Beck Depression Inventory (BDI) is one of the most widely used instruments assessing symptoms of depression. The BDI 
includes 21 items along a 4-point scale (range 0-3) on a 3-day time axis. ${ }^{23}$ Higher scores indicate more severe depressive symptoms, with cut-offs ranging from 'minimal depression', 'mild depression', 'moderate depression' and 'severe depression'. The Cronbach's alphas in the current study were 0.84 pre-CBT, 0.89 post-CBT and 0.92 for the 10 -year follow-up.

\section{The State-Trait Anxiety Inventory}

The State-Trait Anxiety Inventory (STAI) is a commonly used measure of trait and state anxiety, based on a 4-point Likert scale. It consists of 40 questions on a self-report basis. ${ }^{24}$ Higher scores are positively correlated with higher levels of anxiety. It can be used in clinical settings to aid diagnosis of anxiety and to distinguish it from depressive syndromes. Each of the two subscales (state and trait anxiety) consists of 20 questions, rated on a 4-point scale (range $1-4)$. The Cronbach's alphas in the current study were 0.77 preCBT, 0.68 post-CBT and 0.66 for the 10 -year follow-up, and the corresponding values for the state subscale were 0.64 pre-CBT, 0.66 post-CBT and 0.58 for the 10 -year follow-up.

\section{The Somatosensory Amplification Scale}

The Somatosensory Amplification Scale (SSAS) is a 10-item questionnaire assessing how much patients are preoccupied by various symptoms and sensations, including somatic sensations. ${ }^{25}$ These symptoms are mostly not pathological symptoms of serious diseases. The response options range from 1 ('not at all') to 5 ('extremely'). The main difference between the Whiteley Index and the SSAS is that the Whiteley Index focuses on attitudes, concerns, beliefs and fears about health and disease whereas the SSAS focuses on discomfort associated with bodily sensations. ${ }^{25}$ The Cronbach's alphas in the current study were 0.70 pre-CBT, 0.79 for post-CBT and 0.82 for the 10-year follow-up.

\section{The Giessen Subjective Health Complaints}

The Giessen Subjective Health Complaints (GSHC) scale is a symptom scale of bodily symptoms and discomfort. ${ }^{26}$ It includes 60 items each rated on a 5-point Likert scale from 0 , not at all, to 4 , very much. The time span of the scale is 1 week. Total score was computed for the GSHC. The Cronbach's alphas in the current study were 0.91 pre-CBT, 0.86 post-CBT and 0.94 for the 10-year follow-up.

\section{Ten-year follow-up telephone interview}

In addition to the postal questionnaires at the 10-year follow-up, a brief telephone interview was conducted with all the patients. The following questions were asked:

(a) Do you still consider yourself to suffer from Hypochondriacal Disorder? (Yes/No);

(b) Do you use as much time now as you used to, to check for symptoms and scan your body? (Yes/No);

(c) Are you currently using any antidepressants? (Yes/No); and

(d) Have you received any type of psychotherapy after the end of CBT? (yes/no/type of therapy).

Information on age, gender, relationship status, use of medicines, education and work status was also collected from the patients.

\section{Statistics}

Linear mixed models for repeated-measures analysis were implemented using the intention-to-treat principle, so that all patients with baseline data were included in the analysis. Mixed-model analysis (MAR) use data from all informants irrespective of the number

\begin{tabular}{|c|c|c|c|c|}
\hline & Median & IQR & Skewness & Kurtosis \\
\hline \multicolumn{5}{|l|}{ Health anxiety } \\
\hline Whiteley 6-item, total & 21.5 & 4.3 & -1.0 & 2.3 \\
\hline Whiteley 14-item, total & 49.0 & 8.5 & -1.4 & 3.0 \\
\hline $\begin{array}{l}\text { Whiteley 14-item, next of kin } \\
\text { version }\end{array}$ & 31.0 & 10.9 & -0.6 & -0.5 \\
\hline $\begin{array}{l}\text { VAS, tendency to think of } \\
\text { (bodily) symptom }\end{array}$ & 7.2 & 2.9 & -0.8 & 0.8 \\
\hline $\begin{array}{l}\text { VAS, tendency of health } \\
\text { anxiety }\end{array}$ & 6.6 & 3.9 & -0.7 & -0.2 \\
\hline $\begin{array}{l}\text { VAS, tendency to check for } \\
\text { bodily symptoms }\end{array}$ & 6.5 & 4.3 & -0.5 & -0.9 \\
\hline \multicolumn{5}{|l|}{ Quality of life } \\
\hline SF-36, physical role & 50.0 & 75.0 & -0.1 & -1.5 \\
\hline SF-36, emotional role & 33.3 & 66.7 & 0.7 & -0.6 \\
\hline SF-36, physical problems & 92.5 & 15.0 & -1.1 & 0.0 \\
\hline SF-36, social functioning & 61.1 & 33.3 & -0.2 & -0.7 \\
\hline SF-36, mental health & 54.0 & 20.0 & -0.2 & -0.5 \\
\hline SF-36, energy, vitality & 35.0 & 28.8 & 0.6 & 0.0 \\
\hline SF-36, pain & 51.0 & 31.0 & 0.2 & -0.5 \\
\hline $\begin{array}{l}\text { SF-36, general health } \\
\text { perception }\end{array}$ & 46.0 & 26.5 & 0.3 & -0.7 \\
\hline \multicolumn{5}{|l|}{ Somatisation } \\
\hline $\begin{array}{l}\text { Somatosensory Amplification } \\
\text { Scale }\end{array}$ & 26.5 & 8.3 & -0.1 & -0.6 \\
\hline $\begin{array}{l}\text { Giessen Subjective Health } \\
\text { Complaints, total }\end{array}$ & 34.5 & 11.0 & 0.0 & 0.4 \\
\hline \multicolumn{5}{|l|}{ Mental health problems } \\
\hline $\begin{array}{l}\text { State-Trait Anxiety Inventory, } \\
\text { Trait }\end{array}$ & 50.0 & 15.3 & -0.1 & -1.0 \\
\hline $\begin{array}{l}\text { State-Trait Anxiety Inventory, } \\
\text { State }\end{array}$ & 48.0 & 12.3 & -0.8 & 0.3 \\
\hline Beck Depression Inventory & 20.0 & 12.3 & -0.1 & -0.6 \\
\hline
\end{tabular}

of assessment points. No covariates were entered into the model. There are no conclusive tests to prove the assumption of MAR, it is, however, generally considered to be a more realistic assumption as compared with missing completely at random or missing not at random. Standardised mean differences were calculated as the mean difference between two assessment points divided by the baseline s.d., in line with the recommendations of Carlson \& Schmidt and Morris. ${ }^{27,28}$ For the SF-36, independent samples $t$-tests were used to compare patients with Hypochondriacal Disorder with norm scores based on mean, s.d. and sample size. ${ }^{17}$ The normality of the data was examined using skewness and kurtosis, and all continuous measures (except Whiteley Index 14-item total) were well within the recommended ranges $(+/-2)$. All data analyses were conducted using the IBM SPSS Statistics, version 23.

\section{Results}

\section{Participant characteristics}

The mean age at baseline inclusion was 35 years (s.d. $=8.8$, range 21-55), and the participants included a majority of women $(n=$ $41,82 \%)$. In total, $32(64 \%)$ of the participants were employed and $41(82 \%)$ were married or living with a partner. On average, the participants had been diagnosed with Hypochondriacal Disorder for 11.3 years (s.d. $=8.3$ ) at the time of inclusion. The most common disease the patients worried about was cancer, followed by heart-related diseases and neurological diseases, such as multiple sclerosis or amyotrophic lateral sclerosis. There were 34 (68\%) participants who also had lifetime comorbid mental disorders, the most frequent being depression in 17 of the participants 
Table 2 Mental and somatic health at the three assessment points among hypochondriasis patients treated with cognitive-behavioural therapy

\begin{tabular}{|c|c|c|c|c|c|c|c|c|c|c|}
\hline & \multirow[b]{2}{*}{$\begin{array}{l}\text { Pre-treatment, } \\
\text { mean (s.d.) }\end{array}$} & \multirow[b]{2}{*}{$\begin{array}{l}\text { Post-treatment, } \\
\text { mean (s.d.) }\end{array}$} & \multirow[b]{2}{*}{$\begin{array}{l}\text { 10-year follow- } \\
\text { up, mean (s.d.) }\end{array}$} & \multirow{2}{*}{\multicolumn{2}{|c|}{$\begin{array}{l}\text { Pre-Post, } \\
\text { SMD }(95 \% \mathrm{Cl})\end{array}$}} & \multirow{2}{*}{\multicolumn{2}{|c|}{$\begin{array}{l}\text { Pre-follow-up, } \\
\text { SMD }(95 \% \mathrm{Cl})\end{array}$}} & \multicolumn{3}{|c|}{$P$} \\
\hline & & & & & & & & $\begin{array}{l}\text { Pre- } \\
\text { post }\end{array}$ & $\begin{array}{l}\text { Pre-follow- } \\
\text { up }\end{array}$ & $\begin{array}{l}\text { Post- } \\
\text { follow-up }\end{array}$ \\
\hline \multicolumn{11}{|l|}{ Health anxiety } \\
\hline Whiteley 6-item, total & $19.6(4.9)$ & $13.9(4.4)$ & $13.5(4.5)$ & 1.19 & 0.89 to 1.60 & 1.25 & 0.94 to 1.65 & $<0.001$ & $<0.001$ & 0.214 \\
\hline Whiteley 14-item, total & $46.1(10.9$ & $34.1(10.4)$ & 33.5 (10.9) & 1.11 & 0.77 to 1.47 & 1.16 & 0.81 to 1.51 & $<0.001$ & $<0.001$ & 0.190 \\
\hline $\begin{array}{l}\text { Whiteley 14-tiem, next } \\
\text { of kin version }\end{array}$ & $30.4(6.6)$ & $23.2(6.0)$ & $19.9(8.9)$ & 1.09 & 0.63 to 1.48 & 1.60 & 0.93 to 2.15 & $<0.001$ & $<0.001$ & 0.031 \\
\hline $\begin{array}{l}\text { VAS, tendency to think } \\
\text { of bodily symptoms }\end{array}$ & $6.9(2.2)$ & $2.5(2.4)$ & $3.0(3.1)$ & 2.06 & 1.38 to 2.54 & 1.81 & 1.15 to 2.35 & $<0.001$ & $<0.001$ & 0.231 \\
\hline $\begin{array}{l}\text { VAS, tendency of health } \\
\text { anxiety }\end{array}$ & $6.3(2.2)$ & $1.9(1.9)$ & $1.9(1.9)$ & 2.01 & 1.50 to 2.53 & 2.01 & 1.18 to 2.29 & $<0.001$ & $<0.001$ & 0.175 \\
\hline $\begin{array}{l}\text { VAS, tendency to check } \\
\text { for bodily symptoms }\end{array}$ & $6.2(2.7)$ & $1.9(2.0)$ & $3.4(6.1)$ & 1.58 & 1.17 to 2.06 & 1.02 & 0.30 to 1.78 & $<0.001$ & 0.005 & 0.119 \\
\hline \multicolumn{11}{|l|}{ Quality of life } \\
\hline SF-36, physical role & 86.5 (15.9) & $93.7(9.6)$ & $91.0(14.4)$ & -0.45 & -0.73 to -0.21 & -0.28 & -0.56 to -0.05 & $<0.001$ & 0.034 & 0.150 \\
\hline SF-36, emotional role & $34.5(35.0)$ & $85.3(26.4)$ & $75.8(39.0)$ & -1.45 & -1.88 to -0.70 & -1.18 & -1.63 to -0.70 & $<0.001$ & $<0.001$ & 0.122 \\
\hline $\begin{array}{l}\text { SF-36, physical } \\
\text { problems }\end{array}$ & $53.8(38.6)$ & $88.4(24.7)$ & $82.0(34.2)$ & -0.90 & -1.26 to -0.56 & -0.73 & -1.12 to -0.35 & $\mid<0.001$ & $<0.001$ & 0.262 \\
\hline SF-36, social functioning & $55.5(22.8)$ & $76.5(18.6)$ & $73.2(23.5)$ & -0.92 & -1.24 to -0.59 & -0.77 & -1.13 to -0.40 & $<0.001$ & $<0.001$ & 0.306 \\
\hline SF-36, mental health & $52.7(16.0)$ & 75.9 (14.9) & $73.6(17.5)$ & -1.46 & -1.93 to -1.07 & -1.31 & -1.77 to -0.92 & $<0.001$ & $<0.001$ & 0.398 \\
\hline SF-36, energy, vitality & $36.7(21.0)$ & $60.3(15.6)$ & $65.0(58.8)$ & -1.12 & -1.47 to -0.76 & -1.35 & -1.52 to -0.58 & $<0.001$ & 0.002 & 0.578 \\
\hline SF-36, pain & $53.9(23.1)$ & $73.8(21.9)$ & $75.4(24.3)$ & -0.86 & -1.22 to -0.50 & -0.93 & -1.31 to -0.51 & $<0.001$ & $<0.001$ & 0.695 \\
\hline $\begin{array}{l}\text { SF-36, general health } \\
\text { perception }\end{array}$ & $45.1(19.6)$ & $69.8(20.5)$ & $71.7(24.1)$ & -1.26 & -1.50 to -0.83 & -1.36 & -1.56 to -0.86 & $<0.001$ & $<0.001$ & 0.520 \\
\hline \multicolumn{11}{|l|}{ Somatisation } \\
\hline $\begin{array}{l}\text { Somatosensory } \\
\text { Amplification Scale }\end{array}$ & $24.2(6.0)$ & $19.1(5.4)$ & $18.4(6.2)$ & 0.84 & 0.50 to 1.20 & 0.96 & 0.58 to 1.36 & $<0.001$ & $<0.001$ & 0.479 \\
\hline $\begin{array}{l}\text { Giessen Subjective } \\
\text { Health Complaints, } \\
\text { total }\end{array}$ & $109.5(24.2)$ & $91.4(22.3)$ & $88.8(24.1)$ & 0.33 & 0.44 to 1.11 & 0.43 & 0.51 to 1.21 & $<0.001$ & $<0.001$ & 0.488 \\
\hline \multicolumn{11}{|l|}{ Mental health problems } \\
\hline STAl-Trait & $48.8(6.9)$ & $43.6(7.2)$ & $42.8(9.3)$ & 0.77 & 0.42 to 1.11 & 0.88 & 0.46 to 1.31 & $<0.001$ & $<0.001$ & 0.584 \\
\hline STAI-State & $45.5(10.2)$ & $36.3(13.09$ & $33.4(9.6)$ & 0.90 & 0.47 to 1.34 & 1.18 & 0.75 to 1.54 & $<0.001$ & $<0.001$ & 0.131 \\
\hline $\begin{array}{l}\text { Beck Depression } \\
\text { Inventory }\end{array}$ & $15.0(8.3)$ & $6.7(6.5)$ & $7.2(8.7)$ & 1.00 & 0.65 to 1.36 & 0.94 & 0.56 to 1.36 & $<0.001$ & $<0.001$ & 0.727 \\
\hline
\end{tabular}

(34\%: F32) and generalised anxiety (F41.1) in 14 (28\%) of the participants. In most cases, the depression was considered secondary to the patient's Hypochondriacal Disorder, and Hypochondriacal Disorder was always the main diagnosis. In terms of medication use, $4(8 \%)$ of the patients were taking antidepressants at inclusion. Table 1 details the descriptive statistics (median, interquartile range, skewness and kurtosis).

\section{Symptoms of hypochondriasis}

There were significant reductions in levels of Hypochondriacal Disorder scores from pre- to post-CBT, with large effect sizes ranging from a standardised mean difference (SMD) of 0.45 to 2.06. Analyses of the 10-year follow-up-data showed that the treatment gains were well maintained 10 years later, with no statistically significant changes from post-CBT to 10 -year follow-up (see Table 2 for details).

\section{Quality of life}

There were significant improvements across all eight SF-36 subscales from pre- to post-treatment, with effect sizes ranging from a SMD of 0.55 to 1.65 . As with the Hypochondriacal Disorder outcomes, the treatment gains were well maintained at the 10-year follow-up (no significant changes from post-treatment to 10-year follow-up). As displayed in Fig. 1, compared with national norms, patients reported significantly lower levels of quality of life across all eight SF-36 subscales at pre-treatment. At post-treatment, six of the subscales no longer differed from the population norms, whereas the subscales 'physical functioning' and 'role limitation due to physical problems' were still below the norms. The same pattern was observed at 10-year follow-up.

\section{Somatisation}

Both the SSAS and GSHC total score showed significantly reduced levels of somatic complaints from pre- to post-treatment (effect sizes ranging from a SMD of 0.89 to 1.23 ). The 10 -year follow-up analyses show that these treatment benefits were maintained 10 years later, with effect sizes ranging from a SMD of 0.92 to 1.34 .

\section{Mental health problems}

The BDI showed a significant reduction in depression symptoms from pre- to post-treatment, with an effect size of $\mathrm{SMD}=1.11$, and the treatment gains were maintained at the 10-year follow-up assessment. ( $\mathrm{SMD}=0.92)$.

In terms of clinical cut-off, 9 (18\%) and $10(20 \%)$ participants fulfilled the criteria for mild depression (BDI total score $<7$ ) at post- treatment and 10-year follow-up, respectively, compared to $14(28 \%)$ pre-treatment $(P<0.001)$. For moderate depression, 2 (4\%) and $1(2 \%)$ fulfilled the criteria at post- treatment and 10 year follow-up, respectively, compared with $15(30 \%)$ pre-treatment $(P<0.001)$. 


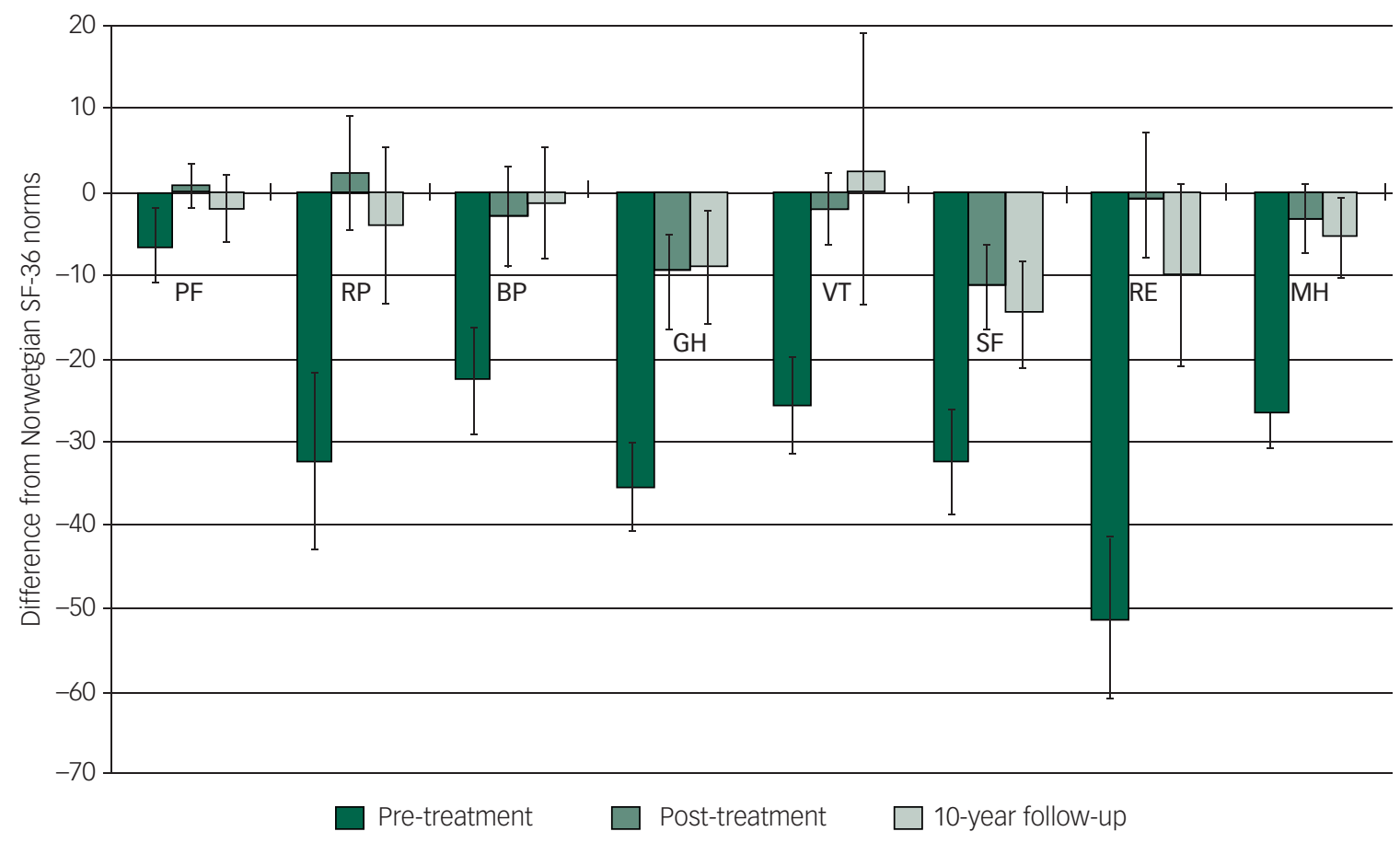

Fig. 1 Health-related quality of life (Short Form 36 Health Survey) at the three assessment points in patients with hypochondriasis treated with cognitive-behavioural therapy, compared with Norwegian norms.

PF, physical functioning; RP, role functioning -physical role limitations due to physical health; BP, bodily pain; GH, general health; VT, vitality; SF, social functioning; RE, role functioning - emotional role limitations due to emotional problems; $\mathrm{MH}$, mental health.

There were also significant improvements in symptoms of anxiety (STAI-Trait and STAI-State) from pre- to post-treatment, with effect sizes of $\mathrm{SMD}=0.69$ and $\mathrm{SMD}=0.79$, respectively. As with the other outcomes, these treatment gains were maintained at 10 -year follow-up, with effect sizes of $\mathrm{SMD}=0.96$ (STAI-Trait) and SMD $=1.21$ (STAI-State).

\section{Ten-year follow-up telephone interview}

At 10-year follow-up, 29 (58\%) of the patients reported that they no longer had Hypochondriacal Disorder; 12 (24\%) reported that they still spent a lot of time checking their body for symptoms; and 10 (20\%) reported using antidepressants. A total of $34(68 \%)$ of the participants reported not receiving any type of therapy since treatment completion.

\section{Discussion}

The aim of this small and uncontrolled treatment study was to investigate the short- and long-term effect of CBT on Hypochondriacal Disorder. In short, treated patients $(n=50)$ displayed significant improvements across all outcome measures, and treatment gains were well maintained even 10 years after treatment completion, suggesting that CBT may have lasting benefits for this patient group. Some important study limitations mean that care should be taken when generalising the results.

Several controlled clinical studies have found that CBT has a positive short-term effect in patients with Hypochondriacal Disorder. In a six-session individual CBT intervention, Barsky \& Ahern found that the positive effect on Hypochondriacal Disorder was maintained at both 6- and 12-month follow-up. ${ }^{13}$ Greeven et al found sustained positive effect of CBT in an 18-month follow- up. ${ }^{29}$ In this long-term follow-up study we found that the shortterm positive effect of 16 sessions of CBT at the 1-year follow-up were maintained after 10 years. Our findings are in line with the conclusion of a recent report from the National Institute of Health Research (NIHR) in the UK that included a 5-year follow-up of patients with Hypochondriacal Disorder receiving CBT. ${ }^{11}$ As the NIHR report showed, the treatment gains were evident across a range of mental and physical health domains, and not just limited to symptoms of Hypochondriacal Disorder. As a result of the lack of a control group and the long time-range between inclusion and end of our study we cannot conclude that the maintenance of the positive clinical status is attributed to $\mathrm{CBT}$ alone, but given the fact that the patients had a long history of Hypochondriacal Disorder, with a mean time of 11.3 years before receiving CBT, it is, in our opinion, a strong indication that the long-term treatment effect is positive. However, we cannot conclude that CBT is the only effective treatment since the study did not include other therapies.

The treatment gains displayed across all self-report questionnaires used in the current study was corroborated by the findings from the telephone interview carried out at the 10-year follow-up assessment, where as many as $58 \%$ of the patients no longer considered themselves as having Hypochondriacal Disorder. Several studies have shown that patients with Hypochondriacal Disorder or excessive health anxiety are high utilisers of healthcare resources. ${ }^{2,6,30-32}$ As the condition in many patients with Hypochondriacal Disorder is left undetected and untreated, ${ }^{2,7}$ there may therefore be substantial socioeconomic benefits in improved diagnostic practices and treatment availability for this patient group. However, the previously mentioned NIHR study found it difficult to show economic benefits for this in terms of quality-adjusted life-years, ${ }^{11}$ but the current study shows a significant improvement in quality of life. 


\section{Methodological limitations}

Some important methodological limitations should be noted. Most importantly, the current study was not a randomised controlled trial. The lack of a control group means that we cannot disregard the possibility that the observed treatment effects may partly be because of time passing or regression to the mean. As such, care should be taking when interpreting the results, and future studies should address this by also including a control group, preferably with an active comparison treatment group. By comparing our findings with trait existing national norms of the SF-36, the obvious weakness of not having a control group was somewhat addressed.

Furthermore, the statistical power of the current study is limited by a relatively small sample size, and larger studies will allow for more detailed analysis of potential moderators in the future. Also, some of the Cronbach's alphas were less than optimal, and the results should be interpreted with this in mind. Moreover, it should be mentioned that only one therapist (I.W.) was involved in treatment. Although this may limit the generalizability of the study, one could argue that continuity was maintained in treatment. Finally, all instrument measures in the current study were based on self-report, and no clinician-verified information was included. However, the next-of-kin version of the Whiteley Index instrument displayed similar treatment gains, indicating the existence of treatment gains across informants.

\section{Strengths}

The current study has the longest follow-up in any Hypochondriacal Disorder treatment study, which is a significant study strength. Also, the drop-out rate across all three assessment points (from pre-treatment to 10 -year follow-up) was only $14 \%$, which is much lower than previous studies of treatment for Hypochondriacal Disorder. ${ }^{13}$

\section{Implications}

In conclusion, this study demonstrates that patients treated with CBT for Hypochondriacal Disorder have significantly reduced health anxiety 1 year after treatment completion and the results are maintained 10 years later. As a result of the long follow-up period and the lack of a control group, the positive results cannot be attributed to the therapy alone and because one therapist treated all the patients this limits the generalizability of the findings. The results are, however, an indication that CBT has a long-lasting effect on Hypochondriacal Disorder.

Kari-Elise Frøystad Veddegjærde (D, MD, Department of Clinical Science, University of Bergen; and Department of Psychiatry and Drug Abuse, Ålesund Hospital, Møre og Romsdal Health Trust, Norway; Børge Sivertsen (D), PhD, Department of Health Promotion, Norwegian Institute of Public Health; Department of Mental Health, Faculty of Medicine and Health Sciences, Norwegian University of Science and Technology (NTNU); and Department of Research and Innovation, Helse-Fonna HF Haugesund Hospital,

Norway; Jens Christoffer Skogen, PhD, Department of Health Promotion, Norwegian Institute of Public Health; and Alcohol and Drug Research Western Norway, Stavanger University Hospital, Norway; Otto Robert Frans Smith, PhD, Department of Health Promotion, Norwegian Institute of Public Health; Ingvard Wilhelmsen, MD, PhD Department of Clinical Science, University of Bergen, Norway

Correspondence: Kari-Elise Frøystad Veddegjærde. Email: karielisev@gmail.com

First received 29 Jan 2019, final revision 29 Oct 2019, accepted 19 Mar 2020

\section{Data availability}

All authors had complete access to the study data.

\section{Acknowledgements}

We wish to thank M.D. Jørn Eilert Bødtker who performed the CIDI interviews.

\section{Author contributions}

All authors have contributed towards the conception and the design. I.W. undertook all the therapies. J.C.S., B.S., O.R.F.S. and K.-E.F.V. have contributed towards analysis and interpretation of data. K.-E.F.V. has drafted the article, and all other authors have contributed towards revising it critically for important intellectual content and final approval of the version submitted.

\section{Declaration of interest}

I.W. gives talks for pharmaceutical companies and has written books about Hypochondriacal Disorder and cognitive-behavioural therapy.

ICMJE forms are in the supplementary material, available online at https://doi.org/10.1192/ bjo.2020.22.

\section{References}

1 World Health Organization. The ICD-10 Classification of Mental and Behavioural Disorders: Diagnostic Criteria for Research. World Health Organization, 1994.

2 Wilhelmsen I. Hypochondriasis and health anxiety. In Encyclopedia of Human Behavior (ed V Ramachandran). Elsevier Inc, 2011.

3 Looper KJ, Kirmayer L. Hypochondriacal concerns in a community population. Psychol Med 2001; 31: 577-84.

4 Bleichhardt G, Hiller W. Hypochondriasis and health anxiety in the German population. Br J Health Psychol 2007; 12: 511-23.

5 Sunderland M, Newby JM, Andrews G. Health anxiety in Australia: prevalence, comorbidity, disability and service use. Br J Psychiatry 2013; 202: 56-61.

6 Fink $P$, Ornbol $E$, Christensen $K S$. The outcome of health anxiety in primary care. A two-year follow-up study on health care costs and self-rated health. PLOS One 2010; 5: e9873.

7 Asmundson GJ, Abramowitz JS, Richter AA, Whedon M. Health anxiety: current perspectives and future directions. Curr Psychiatry Rep 2010; 12: 306-12.

8 Savikko A, Alexanderson $\mathrm{K}$, Hensing G. Do mental health problems increase sickness absence due to other diseases? Soc Psychiatry Psychiatr Epidemiol 2001; 36: 310-6.

9 Mykletun A, Heradstveit O, Eriksen K, Glozier N, Overland S, Maeland JG, et al. Health anxiety and disability pension award: the HUSK study. Psychosom Med 2009; 71: 353-60.

10 Noyes R. The transformation of hypochondriasis in British medicine, 16801830. Soc Hist Med 2011; 24: 281-98.

11 Tyrer $P$, Salkovskis $P$, Tyrer $H$, Wang $D$, Crawford MJ, Dupont S, et al. Cognitivebehaviour therapy for health anxiety in medical patients (CHAMP): a randomised controlled trial with outcomes to 5 years. Health Technol Assess 2017; 21: 1-58.

12 Warwick HMC, Clark DM, Cobb AM, Salkovskis PM. A controlled trial of cognitive-behavioural treatment of hypochondriasis. Brit J Psychiat 1996; 169: 189-95.

13 Barsky AJ, Ahern DK. Cognitive behavior therapy for hypochondriasis: a randomized controlled trial. JAMA 2004; 291: 1464-70.

14 Robins LN, Wing J, Wittchen HU, Helzer JE, Babor TF, Burke J, et al. The Composite International Diagnostic Interview. An epidemiologic Instrument suitable for use in conjunction with different diagnostic systems and in different cultures. Arch Gen Psychiatry 1988; 45: 1069-77.

15 Salkovskis PM, Thorpe SJ, Wahl K, Wroe AL, Forrester E. Neutralizing increases discomfort associated with obsessional thoughts: an experimental study with obsessional patients. J Abnorm Psychol 2003; 112: 709-15.

16 Metcalfe J, Shimamura AP. Metacognition: Knowing about Knowing. MIT Press, 1994.

17 Loge JH, Kaasa S. Short Form 36 (SF-36) Health Survey: normative data from the general Norwegian population. Scand J Soc Med 1998; 26: 250-8.

18 Pilowsky I. Dimensions of hypochondriasis. Br J Psychiatry 1967; 113: 89-93.

19 Veddegjaerde KEF, Sivertsen B, Wilhelmsen I, Skogen JC. Confirmatory factor analysis and item response theory analysis of the Whiteley Index. Results from a large population based study in Norway. The Hordaland Health Study (HUSK). J Psychosom Res 2014; 77: 213-8.

20 Welch PG, Carleton RN, Asmundson GJ. Measuring health anxiety: moving past the dichotomous response option of the original Whiteley Index. J Anxiety Disord 2009; 23: 1002-7.

21 Ware JE, Snow KK, Kosinski M, Gandek B. SF-36 Health Survey Manual and Interpretation Guide. Medical Outcomes Trust, 1993.

22 Bech P, Kastrup M, Rafaelsen OJ. Mini-compendium of rating scales for states of anxiety depression mania schizophrenia with corresponding DSM-III syndromes. Acta Psychiatr Scand Suppl 1986; 326: 1-37. 
23 Beck AT, Ward CH, Mendelson M, Mock J, Erbaugh J. An inventory for measuring depression. Arch Gen Psychiatry 1961; 4: 561-71.

24 Spielberger CD, Gorsuch RL, Lushene R, Vagg PR, Jacobs GA. Manual for the State-Trait Anxiety Inventory. Consulting Psychologists Press, 1983.

25 Barsky AJ, Wyshak G, Klerman GL. The somatosensory amplification scale and its relationship to hypochondriasis. J Psychiatr Res 1990; 24: 323-34.

26 Vassend O. Dimensions of negative affectivity, self-reported somatic symptoms, and health-related behaviors. Soc Sci Med 1989; 28: 29-36.

27 Carlson KD, Schmidt FL. Impact of experimental design on effect size: findings from the research literature on training. J Appl Psychol 1999; 84: 851-62.

28 Morris SB. Estimating effect sizes from pretest-posttest-control group designs. Organ Res Methods 2008; 11: 364-86.
29 Greeven A, van Balkom AJ, van der Leeden R, Merkelbach JW, van den Heuve $\mathrm{OA}$, Spinhoven P. Cognitive behavioral therapy versus paroxetine in the treatment of hypochondriasis: an 18-month naturalistic follow-up. J Behav Ther Exp Psychiatry 2009; 40(3): 487-96.

30 Savikko A, Alexanderson K, Hensing G. Do mental health problems increase sickness absence due to other diseases? Soc Psychiatry Psychiatr Epidemiol 2001; 36: 310-6.

31 Gureje O, Ustun TB, Simon GE. The syndrome of hypochondriasis: a crossnational study in primary care. Psychol Med 1997; 27: 1001-10.

32 Creed F, Barsky A. A systematic review of the epidemiology of somatisation disorder and hypochondriasis. J Psychosom Res 2004; 56: 391-408.

OPEN 